\title{
Integrated Hazardous Materials Management: Combining Requirements from Various Environmental Legislations to Enable Effective Business Compliance Processes in Industries
}

\author{
Robert Miehe',", Sebastian Mueller', Ralph Schneider', Sylvia Wahren', and Markus Hornberger ${ }^{1}$ \\ 1 Fraunhofer Institute for Manufacturing Engineering and Automation (IPA), Nobelstrasse 12, 70569 Stuttgart, Germany \\ \# Corresponding Author / E-mail: Robert.Miehe@ipa.fraunhofer.de, TEL: +49-(0)711-970-1424, FAX: +49-(0)711-970-1002
}

KEYWORDS: Process engineering, Hazardous substances, Environmental compliance

\begin{abstract}
Enhanced global trade forces companies to comply with a variety of environmental legislations each being subject to continuous modifications. During the past years the number of environmental legislations increased dramatically while law enforcement agencies expanded their active analysis of companies and their products. The number of companies being accused to sell non-compliant products by both enforcement authorities and competitors increases ever since. The compliance of companies and products is greatly dependent on their internal processes and their ability to adjust to changes. In this paper we introduce a highly applicable process aiming to ensure compliance with various hazardous substances regulations that has been tested successfully in over 70 companies of different industries in Germany. Thereby, we define essential steps, present a standardized approach for material, substance and risk assessment for articles based on existing standards (ISO 31000, 14040, 14044 and EN50581) and discuss its applicability to different business types related to size, number of employees, suppliers and materials. While the process is found to be appropriate for all business types, the time span required for realization varies significantly. Especially large companies tend to suffer from bureaucratic structures, while small and micro sized companies rather lack of knowledge and availability of resources.
\end{abstract}

Manuscript received: October 23, 2014 / Revised: April 22, 2015 / Accepted: May 5, 2015

\section{Introduction}

Green manufacturing is one of today's major challenges to industries. ${ }^{1}$ Besides the reduction of material and energy use, policies seek to prevent humans and the environment from certain hazardous substances. Most governments have realized their obligation to ban these substances from consumer products as well as their use in manufacturing processes. During the past years the global quantity of environmental legislation entered into force has thus increased dramatically as illustrated in Fig. $1 .^{2}$ Most relevant legislations in the field of hazardous substances in consumer products within the European Union (EU) are ELV, WEEE, RoHS, and REACH. ${ }^{3-6}$ Other countries and regions will or have introduce(d) similar regulations with slightly different requirements, e.g. China-RoHS, China-REACH, Korea-REACH. A further increase of the quantity of environmental legislations is presumed to be likely, as many developing and transition countries have not yet initiated comprehensive environmental legislative systems. Additionally, many environmental issues remain not yet targeted by legislations in developed countries.

Generally, regulation specifications in the context of hazardous

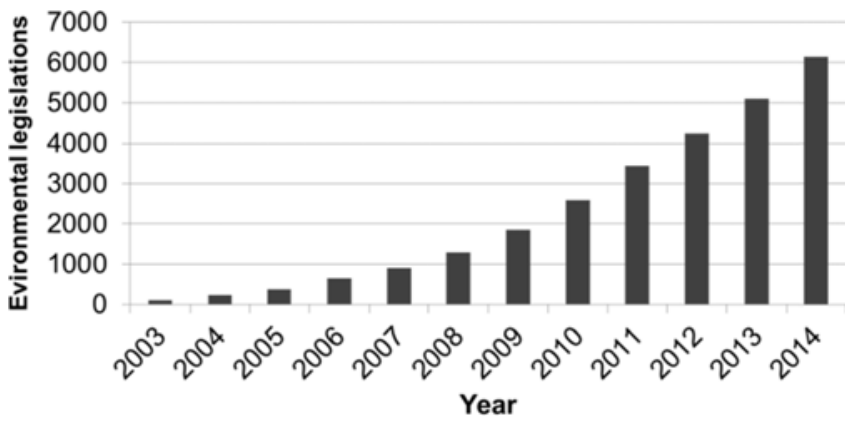

Fig. 1 Amount of global environmental legislations ${ }^{2}$ 
materials cover scope of application, maximum permissible values, exclusions, exemptions and documentation requirements for substances in either products or applications. For instance, the RoHS directive covers product specific targets while REACH focuses on both the use of a substances and their application in articles. The majority of these environmental legislations have to be considered dynamic, as they are subject to frequent amendments. A future increase of product or process related substances restrictions within single regulations thus is inevitable(e.g. continuous updates of REACH candidate list; REACH Annex XVI, XVII; RoHS Annex II, III, IV).

Violations against European substances legislations are subject to national dispensation of justice. Penalties thus may vary significantly between EU member states. While Germany determines a maximum penalty of 100,000 Euro for a single violation, other states, e.g. Ireland or Portugal, charge up to a few million. Offenses in this area, however, do not only lead to heavy penalties for companies but also for decision makers. In cases of action against better judgement, imprisonment of responsible persons, e.g. CEOs, are possible.

The compliance of companies and products with environmental legislations in the EU are frequently monitored by nationally installed enforcement agencies. Over the past couple of years, these agencies have expanded activities. The most widely recognized case of noncompliance has been shown by Daimler in 2013. The use of a banned cooling agent by regulation (EC) No 842/2006 in Daimler vehicles forced the French government to refuse market access. ${ }^{7}$ Although concrete numbers were not published by Daimler, estimations account for 4500 vehicles not being sold in France. ${ }^{8}$

A powerful tool for the communication of such violations within the EU is the Rapid Alert System for non-food (RAPEX). ${ }^{9}$ Via RAPEX notification reports of products posing a serious risk to the health and safety of consumers are published on a weekly basis. Besides the type of risk, RAPEX discloses the brand and product name as well as type and number of model, country of origin. A company finding its product being reported on this platform will suffer from substantial monetary losses and reputation damage. From a government perspective, RAPEX has become an influential instrument to force companies into increased compliance endeavors.

Furthermore, an increased number of competitors take misconduct to court. In the EU it has become method of best practice within a company's benchmarking to separately analyze competitor products regarding the compliance with environmental legislations and report failures to enforcement agencies.

In summary, the pressure on companies to ensure legal compliance over their entire supply chain and product life cycle is continuously increasing. This eventually increases complexity of business and puts high pressure especially on global players with multiple thousand active suppliers and hundreds of global sales regions. Most important for industrial enterprises is, however, the avoidance of undesired obsolescence of their products and loss of reputation and economical throwbacks.

Regarding companies, we identify seven major problem areas.

(1) Decision makers lack in explicit knowledge about relevant legislations and methods.

(2) The product spectrum is source of further complexity. Following the current trend towards mass personalization, companies often manufacture a wide variety of products each possibly being subject to other legislations and exemptions across the globe.

(3) Lack of information about substances used in products and applications across the supply chain (e.g. spare parts, bought-in parts).

(4) Comprehensive data management represents another source of concern. The value-added process of industrial companies requires the application of different data bases, e.g. for design (CAD) and resource planning (ERP). In order to guarantee global environmental compliance, up to date information about prohibited substances have to be present at each level of business, especially $R \& D$, procurement, sales as well as quality, project and environmental management. This again requires an interface data base that commonly does not exist or is poorly managed. Additionally, often imprecise definition of materials and other attributes makes it difficult to overlook the entire material spectrum.

(5) Purchase and sales in terms of high numbers of suppliers and sales regions with low levels of informational connection additionally increase complexity.

(6) Responsibilities concerning hazardous material management within industrial enterprises are not clearly appointed.

(7) As a consequence of (1)-(6) companies find it hard to establish an integrated management approach to address the above mentioned challenges properly.

Considering the information above, three main challenges for further research occur:

- What key elements are essential for addressing the requirements of various substances regulations?

- How can an integrated management system that covers these obligations be designed and implemented?

- How do specifics of different business types affect the implementation of legislative requirements?

Recently, scientific improvements in this area have been rare. In this paper we therefore introduce a highly applicable approach that has been tested successfully in over 70 companies among different industries in Germany.

\section{Basics and Boundaries}

Although many authors have aimed at defining the term business process its understanding remains universal. ${ }^{10-12}$ In the following, we refer to the most common definition from Davenport and Short (1990). A business process is a "[...] set of logically related tasks performed to achieve a defined business outcome". ${ }^{10}$

Generally, industrial companies seek standardization of administrative processes as they do not directly add value to final products. Many authors have highlighted benefits from business process standardization. ${ }^{12,13}$ These are essentially improving operational performance, reducing processing costs, increasing consumer satisfaction and enabling compliance with regulations. ${ }^{14}$

In this context, a variety of management systems have been discussed in literature and successfully implemented in industries. On this basis standards have been developed and legislations have been introduced, including quality, ${ }^{15}$ environment ${ }^{16}$ and energy ${ }^{17}$ as well as EMAS (acronym for Eco-Management and Audit Scheme) $)^{18}$ and 
compliance management. ${ }^{19}$ None of these involve concrete instructions for hazardous materials management in companies.

The implementation of an hazardous materials management (HMM) is essential for global compliance in the field of environmental law and might be linked to a compliance management system as described in. ${ }^{19}$ While formerly being related to finance and health care, the term compliance today refers to the general adherence of all relevant legislations. ${ }^{20-22}$ A distinct focus on substances in industrial products was not found in any of these sources.

Nevertheless, companies have to face a certain risk of not being compliant. This might either be caused by lack of external (e.g. relevant requirements) or internal information (substances in applied materials). Both, the term risk as well as concepts for risk management have been discussed in literature excessively. ${ }^{23-27}$ According to the International Organization for Standardization, the term risk describes the "effect of uncertainty on objectives". ${ }^{28}$ In the context of HMM risk is understood as the probability of being non-compliant. Thereby, HMM essentially follows recommendations from ISO 31000 as displayed in Fig. 2. ${ }^{29}$

\section{Legal Requirements}

In the following we illustrate the introduction of HMM using the example of RoHS and REACH. Therefore, the following paragraphs present essential legal requirements that arise from these three legislations.

The RoHS2 directive (2011/65/EU) is specifically designed for the EEE industry. ${ }^{5}$ It restricts the use of certain hazardous substances, i.e. the heavy metals lead $(\mathrm{Pb})$, mercury $(\mathrm{Hg})$, cadmium $(\mathrm{Cd})$ and chromium IV (Cr6) as well as the flame retardants polychlorinated biphenyles (PBB) and polybrominated diphenyl ethers (PBDE). Recently, the EU has released four additional substances (DEHP, BBP, DBP, DIBP) each to be restricted under RoHS2 from January $2019 .{ }^{30}$ These substances are permitted to certain maximum permissible values $(0.01 \% \mathrm{w} / \mathrm{w}$ for cadmium, $0.1 \% \mathrm{w} / \mathrm{w}$ for the rest) related to the homogeneous material. The European directive currently grants over 90 exemptions (Annex 3 and 4) for applications where these substances are not easily substituted. In summary, the European RoHS2-Directive essentially requires the compliance with its maximum permissible

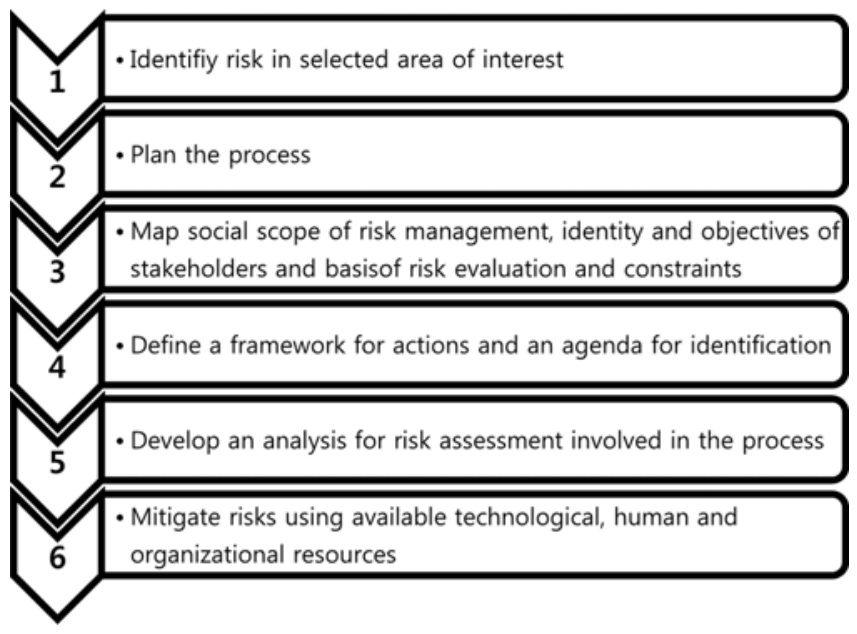

Fig. 2 ISO 31000 risk management implementation ${ }^{29}$ values as well as a technical documentation. Similar legislations are found in many other countries and regions, including China, Japan, Korea, the Eurasian Economic Community customs union, etc., each having slightly deviating requirements.

The regulation (EC) No 1907/2006 concerning the Registration, Evaluation, Authorization and Restriction of Chemicals (REACH) is a centerpiece of European chemical law and its efforts to harmonize jurisdiction. ${ }^{6}$ Based on the principle of direct industrial responsibility it targets all chemical substances that are placed on the EU market (scope of REACH). Apart from its multiple specifications, its requirements may essentially being summarized as: (1) registration ("no data, no market" - all chemical substances), (2) information requirements (article 33) related to the SVHC-candidate list, (3) authorized substance use (annex XIV) and (4) restriction (annex XVII). While the RoHS directive sets a uniform reference value (homogenous material) on article level, REACH currently sets a variety of different reference values regarding articles or application.

Similar legislations have been introduced in many other countries and regions, including parts of the USA, China, Korea, Turkey, Japan, the Eurasian Economic Community customs union, etc., again each having slightly deviating requirements.

\section{An Approach towards Standardized Hazardous Materials Management}

HMM covers five basic elements: (1) targets, (2) actual company status, (3) risk assessment, (4) required actions and (5) long term validation. These five categories correspond to the PDCA - cycle and are furthermore divided into 14 steps of concrete actions as displayed in Table 1.

The following subsections discuss each aspect of HMM briefly.

Table 1 HMM - 14 steps towards global environmental compliance

\begin{tabular}{|c|c|c|}
\hline Step & Action & Element \\
\hline 1 & $\begin{array}{l}\text { Identification of legal and customer } \\
\text { requirements }\end{array}$ & \multirow{2}{*}{ Targets } \\
\hline 2 & $\begin{array}{l}\text { Identification of documentation } \\
\text { requirements }\end{array}$ & \\
\hline 3 & Clarification of affected products & \multirow{3}{*}{$\begin{array}{l}\text { Actual } \\
\text { company } \\
\text { status }\end{array}$} \\
\hline 4 & Status-Quo evaluation of suppliers & \\
\hline 5 & $\begin{array}{l}\text { Status-Quo evaluation of materials / } \\
\text { substances }\end{array}$ & \\
\hline 6 & Identification of material / substance risk & \multirow{2}{*}{$\begin{array}{c}\text { Risk } \\
\text { assessment }\end{array}$} \\
\hline 7 & $\begin{array}{c}\text { Identification of overall risk and impact } \\
\text { assessment }\end{array}$ & \\
\hline 8 & $\begin{array}{l}\text { Derivation and execution of additional } \\
\text { information gathering }\end{array}$ & \multirow{3}{*}{$\begin{array}{l}\text { Required } \\
\text { actions }\end{array}$} \\
\hline 9 & $\begin{array}{l}\text { Initiation of HMM-controls and supplier } \\
\text { audits }\end{array}$ & \\
\hline 10 & $\begin{array}{l}\text { Re-Evaluation of suppliers, manufacturers } \\
\text { and material }\end{array}$ & \\
\hline 11 & $\begin{array}{l}\text { Development, integration and continuous } \\
\text { improvement of process and work } \\
\text { instructions }\end{array}$ & \multirow{4}{*}{$\begin{array}{l}\text { Long term } \\
\text { validation }\end{array}$} \\
\hline 12 & IT integration and support & \\
\hline 13 & Documentation & \\
\hline 14 & HMM system audit & \\
\hline
\end{tabular}




\subsection{Identification of Legal and Customer Requirements}

First, a company has to identify relevant legislations in each distribution country. Two approaches are common: (1) the acquisition of country warrants of apprehension from a specialized service provider. These services are generally expensive and limited to a single product. (2) A self-employed documentation of relevant legislations is by far less expensive and data sources are manifold. ${ }^{31-33}$ Additional customer requirements, e.g. aluminum free, may significantly affect product development. Generally, these requirements should be clear before design and manufacturing, e.g. from contracts, terms and conditions, etc. In certain industries, e.g. consumer electronics or industries with long development periods, additional customer requirements might occur after sales start. In certain cases a company thus is forced to re-design a product which decreases earnings per unit significantly. Customer requirements have to be documented similar to legal requirements.

In both cases, we propose a two-step approach: (1) the construction of a requirement matrix followed by (2) a detailed description of legislation specific requirements. The matrix guarantees a comparatively effective overview of relevant legislations and enables a company to develop its distinct definition of a certain legal group according to relevant sales regions (e.g. EU-RoHS + Korea-RoHS + China-RoHS).

\subsection{Identification of Documentation Requirements}

According to Article 7(b) of 2011/65/EU (EU-RoHS2) manufacturers are required to draw up a "[...] technical documentation and carry out the internal production control procedure in line with module A of Annex II to Decision No 768/2008/EC [...]". No 768/2008/EC regulates fundamentals of CE labeling according to article 30 of Regulation No 765/2008. ${ }^{35}$ With the CE label a manufacturer declares compliance with all relevant EU regulations and requirements. For EEE products RoHS2 compliance thus is a basis for the CE labeling. Decision No 768/2008/EC essentially demands for internal manufacturing controls and technical documentation. EEE product specific documentation requirements are normed within EN $50581 .{ }^{36}$ Required contents of a technical documentation according to EN 50581 are: (1) a general description of the product, (2) documents covering applied materials, components and assembly groups, (3) information regarding connection of previously described documents as well as (4) a list of standards and technical specification and norms that have been applied. A manufacturer is obliged to determine, collect and evaluate relevant information as well as secure validation. Approved documents are standards, supplier / manufacturer / material declaration and analytical results.

Currently, EN 50581 does not exhibit validity for REACH. Project experience has however shown sound compatibility.

\subsection{Clarification of Affected Products}

As the first step of internal status-quo analysis a clarification of affected products and substances has to be conducted, in this case according to REACH and RoHS. The clarification occurs within customer / supply chain communication.

\subsection{Status-Quo Evaluation of Suppliers}

After the clarification of affected substances and products, status-quo information of supplier and manufacturer communication / rating is gathered. Within this step two major topics should be analyzed: (1) fundamentals of supplier communication and (2) methods of supplier rating.

First, supplier communication should cover all relevant legislations. Many companies claim compliance of supplier goods with relevant legislations but assure themselves inadequately. The development of standardized supplier / manufacturer communication letters has shown to be most effective. In this context, phrasing should be legally harmonized. Furthermore, written and signed letters are the only acceptable form of communication and legal references should be updated frequently.

Depending on size, companies generally have implemented a system of supplier rating. General methods of supplier rating have been described in detail. ${ }^{37}$ Common measures are supplier quality, constancy and branch codes. Since suppliers may be spread globally, another measure of credibility may be appropriate according to EN $50581 .^{36}$ Information from various countries have been shown to not be equally reliable. The corruption perception index, annually released by Transparency International, provides a sound measure for supplier information credibility and is widely accepted by enforcement agencies. ${ }^{38}$ In addition, it is easily implemented and combinable with other measures due to its simple scale $(0-100)$. In summary, supplier rating may be carried out as displayed in Table 2 . Thereby, measure grading is autonomously selectable by a company.

Each supplier has to be rated according to the previously defined measures. This enables a company to define risk categories with respect to its ratio.

\subsection{Status-Quo Evaluation of Materials and Substances}

The EN 50581 is specifically designed for RoHS. It however has also demonstrated great applicability regarding the requirements of REACH. According to the EN 50581, at least one document is required for each material, substance or module that remains in the product verifying its compliance with the RoHS directive. A product may not be labeled compliant until at least one document for each material, substance or module is obtained. On the basis of the German Umbrella Association for the Electric and Electronic Industry $(\mathrm{ZVEI})^{39}$ we identify five feasible strategies for material evaluation:

(1) experience values,

(2) supplier declaration,

(3) material declaration based on

- standards,

- manufacturer information (e.g. material data sheet)

- analysis (e.g. XRF screening)

(4) full material declaration.

It is thus feasible for any company to request at least one document for both RoHS and REACH relevant substances.

Table 2 Supplier measures and rating example

\begin{tabular}{cc}
\hline Measure & Rating \\
\hline CPI & 100 \\
\hline Supplier quality & 80 \\
\hline Supplier constancy & 50 \\
\hline$\ldots$ & $\ldots$ \\
\hline Summary & 230
\end{tabular}




\subsection{Identification of Material Risk}

Following the steps of a Life Cycle Assessment (LCA) as standardized under ISO 14040 and 14044, four main phases are to be executed as displayed in Fig. 3..$^{40,41}$

As goal and scope of material evaluation have been discussed above, the following paragraphs will focus on the inventory analysis of articles under RoHS and REACH. An approach for impact assessment is described in Subsection 4.6.

In order to comprehensively rate materials and substances in articles four steps are required:

\subsubsection{Definition of Material Classes}

As most companies already sort materials in internally agreed upon classes, this step is only mandatory if a classification has not yet been established. A common classification according to IEC 62474 and IEC 62321-2 is displayed in Table 3. ${ }^{42,43}$

\subsubsection{Initial Evaluation of Material Classes Based on Experience Values}

The initial material and substance evaluation is entirely based on analytical experience, e.g. from IEC 62321-2. Other sources might be analyses publications from government agencies. Thereby rating is carried out on a material category level. This approach is rather fast and offers a sound start for companies that have not applied HMM before. On a long term, it however reveals great weaknesses since it does not respond to specifics within a material category and additional requirements from other legislations are not easily transferred. An integral evaluation thus is inevitable.

As the initial evaluation aims at defining recommendations for a detailed rating, a categorization of material categories in three levels of urgency has been shown to be most applicable:

- $\mathrm{H}=$ High urgency, if many cases of non-compliance have been reported within this material class

$M=$ Medium urgency, if a justifiable amount of cases of noncompliance has been reported within this material class

- $\mathrm{L}=$ Low urgency, if no cases of non-compliance are known within this material class

\subsubsection{Definition of Requirements for an Integral Evaluation of Each Material}

An integral evaluation of materials and substances requires a large

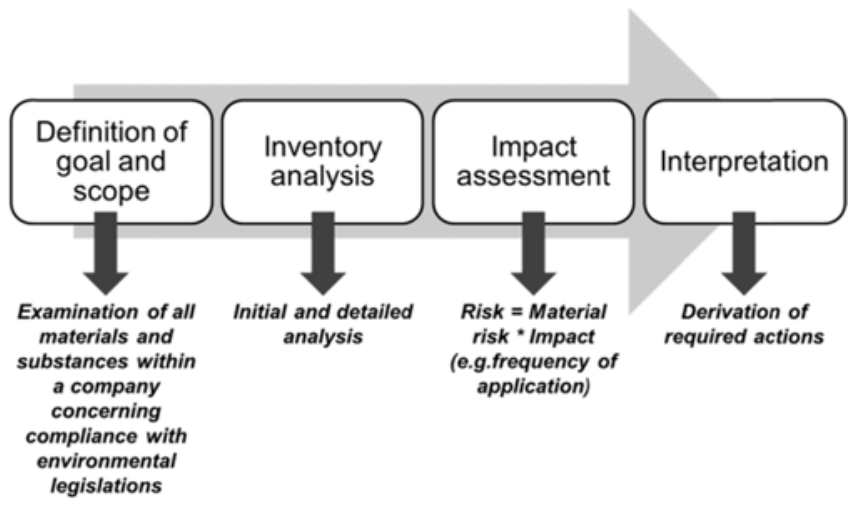

Fig. 3 Approach to accurate material evaluation in industries on the basis of ISO 14040 and $14044^{40,41}$ quantity of information. In the context of a reliable technical documentation (EN 50581), the following points summarize to be collected data of capital importance:

- Material / article number and denotation,

- Frequency of use and / or quantity of application in different modules,

- Use of standards / list of standards per product,

- Confirmation of RoHS compliance / use and duration of exemptions used for compliance,

Completion of all REACH requirements regarding a specific substance (article 33, annex XIV and XVII) and

- Source of information.

An appropriate material rating is constructed hierarchical. According to the urgency rating of material categories within the previous step an increased quantity of requirements should be defined with the degree of urgency (L, M, H).

\subsubsection{Integral Evaluation and Classification of Each Material in Risk Categories}

The integral material evaluation allows a by far superior rating compared to an initial estimation based on experience. Thereby, each material and component that is affected within a company is analyzed in detail and apportioned in chemical components. Accepted methods for identification of chemical composition are technical standards,

Table 3 Material and substance classification according to IEC 62474 and IEC $62321-2^{42,43}$

\begin{tabular}{|c|c|c|}
\hline & $\mathrm{M} / 0$ & 1. Drawing parts \\
\hline \multirow{17}{*}{$\begin{array}{c}\text { IEC } \\
62474\end{array}$} & $\mathrm{M} / 1$ & 2. Materials \\
\hline & M-001 & Stainless steel \\
\hline & M-002 & Other ferrous alloys, Non-Stainless steels \\
\hline & M-003 & Aluminum and its alloys \\
\hline & M-004 & Copper and its alloys \\
\hline & M-005 & Magnesium and its alloys \\
\hline & M-006 & Nickel and its alloys \\
\hline & M-007 & Zinc and its alloys \\
\hline & M-008 & Precious metals \\
\hline & M-009 & Other non-ferrous metals and alloys \\
\hline & M-010 & Ceramics / Glass \\
\hline & M-011 & Other inorganic materials \\
\hline & M-012 & PolyVinyChloride (PVC) \\
\hline & M-013 & Other thermoplastics \\
\hline & M-014 & Other plastics and rubber \\
\hline & M-015 & Other organic materials \\
\hline & & 3. Components \\
\hline \multirow{11}{*}{$\begin{array}{c}\text { IEC } \\
62321-2\end{array}$} & $\mathrm{~B} / 2$ & 3.1 Coatings \\
\hline & $\mathrm{Z} / 3$ & 3.2 HBC materials \\
\hline & $\mathrm{E} / 4$ & 3.3 PWB electronic parts \\
\hline & $\mathrm{O} / 5$ & 3.4 Optical components \\
\hline & $\mathrm{F} / 6$ & 3.5 Formed components \\
\hline & $\mathrm{M} / 7$ & 3.6 Mechanical components \\
\hline & $\mathrm{G} / 8$ & 3.7 Body parts \\
\hline & $\mathrm{N} / 9$ & 3.8 Standard components \\
\hline & $\mathrm{K} / 10$ & 3.9 Catalogue components \\
\hline & $\mathrm{S} / 11$ & 3.10 Other purchased parts \\
\hline & $\mathrm{O} / 12$ & 3.11 OEM products \\
\hline
\end{tabular}


material declarations being linked to specific material data sheets and analytical test results (e.g. X-ray fluorescence or wet chemistry analysis). The quantity of required documents should be based on the previously identified degree of urgency (L, M, H), e.g. one document suffices for L-materials, while at least two documents with one being a technical analysis should be gathered for a material of high urgency.

This method is, however, associated with great efforts but allows complete coverage of all relevant legislations and allows long term validity due to its overall transparency. Against the background of the discussed exponential increase of environmental legislations only an integral material evaluation facilitates long term validation.

\subsection{Risk and Impact Assessment}

Risk assessment is an integral part of HMM as it displays the current level of compliance and allows the deviation of urgent actions. As described in Section 2, risk refers to the probability of failing to be compliant. Various methods of risk assessment in industrial enterprises have been discussed in literature and successfully implemented ${ }^{44}$ In the context of compliance concerning hazardous substances restrictions, risk may be defined as material rating multiplied with the impact of non-compliance. Frequency of use or quantity of application of a single material in different modules have been shown to be useful indicators for the impact of non-compliance.

Although not exposing each case of risk consistently, the implementation of a risk matrix has been shown to be most applicable in practice. Fig. 4 illustrates an example of a risk matrix.

\subsection{Derivation and Execution of Additional Information Gathering}

In a next step specific actions are allocated to each of the categories. While for materials from low risk categories a single supplier / manufacturer declaration is satisfactory, additional control sample analysis (e.g. XRF) are appropriate. Continuous analytical testing is advisable for materials and components from high risk categories. On a long term high risk categories should be substituted. Table 4 exemplifies the initiation of actions according to categories from previously defined risk matrix.

\subsection{Initiation of HMM-Controls and Supplier Audits}

An appropriate HMM consists of a tailored control system. Based

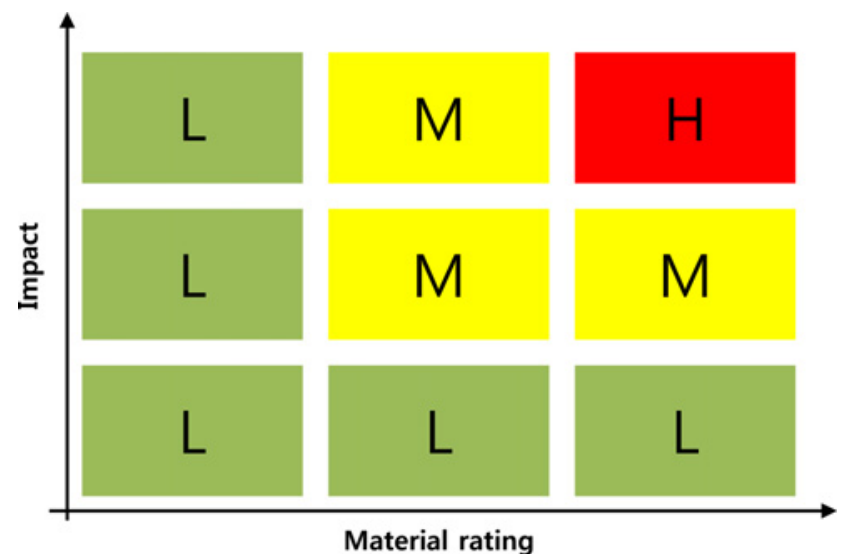

Fig. 4 Risk matrix on the previously assessed risk of a material/substance, control plans have to be developed for initial sampling and incoming goods. Thereby, it has to be defined at what stage and frequency specific materials, substances and articles shall be tested, e.g. via X-ray fluorescence screening or infrared spectroscopy. Commonly, medium risk materials/substance are tested randomly, while high risk materials/ substance have to be tested frequently.

Supplier and manufacturer audits are common for company and product specific qualification and an essential element of many quality and environmental management systems. In the context of HMM supplier and manufacturer audits are to be conducted for medium and high risk suppliers that might not easily be substituted or strategically relevant. Therefore, companies have to develop a tailored audit scheme and specifically qualify their employees to execute audits, interpret its results and derive proper actions.

\subsection{Re-Evaluation of Suppliers, Manufacturers and Materials}

All actions have to be conducted frequently and results have to be integrated in the continuous risk assessment of materials and suppliers. Generally, a company is free to determine intervals of re-evaluation. Against the background of continuous legal modifications, practice has however shown that periods of six to twelve months are most effective.

4.11 Development, Integration and Continuous Improvement of an Overall HMM Process and Work Instructions for Design, Purchase, Sales, Control, and Analysis

The first step of long term HMM validation is the development of an appropriate overall process. The process is the centerpiece of HMM. It has to cover all essential steps of compliance management, responsibilities and has to be practical. After its integration a system of continuous improvement is required in order to guarantee compliance while regulations may be amended. An example for an appropriate HMM process covering all essential steps is found in Appendix A.

Work instructions are present in nearly every industrial company in order to guarantee standardized operational procedures. Affected divisions are essentially $\mathrm{R} \& \mathrm{D}$, purchase, sales as well as project, quality, and environmental management. A variety of urgent questions have to be answered within this step, e.g.:

- At what point does the developer need to be informed about the legal applicability of certain materials?

- Who is responsible for material and component clearance? How shall compliance be guaranteed and documented before material and component clearance?

- How shall procedural methods of incoming inspection be extended in order to fulfill previously defined requirements of control and analysis?

- Etc.

HMM specific work instructions have to be subject to continuous improvement.

Table 4 Initiation of actions according to risk category

\begin{tabular}{cc}
\hline $\mathrm{L}$ & Supplier / Manufacturer declaration \\
\hline $\mathrm{M}$ & Additional control sample analysis \\
\hline $\mathrm{H}$ & Additional continuous analytical testing \\
\hline
\end{tabular}




\subsection{IT Integration and Support}

IT integration and support is essential for long term compliance From stage one of product development legal compliance has to be assured.

Developer, purchase and sales employee have to have access to accurate information at the right time. A developer needs to know what materials he can use for a legally compliant design. A purchaser needs to know what documents and analytical test he needs to run for a certain material. In this sense, a company's IT structure has to represent the previously defined process and work instructions. A sound IT environment thus demands for an adequate interface between data bases. As discussed above, a variety of enterprises have developed IT solutions for environmental compliance interfaces. ${ }^{45-48}$ A serious discussion of pro and cons of different concepts has to be abandoned at this point.

\subsection{Documentation}

According to documentation requirements, defined in step three, long term validation closes with the compilation and continuous actualization of the technical documentation. Besides its external purpose, the assurance of compliance against law enforcement agencies, it has to serve as a tool for knowledge transfer within an organization. Due to increasing fluctuation, companies a forced to effectively pass knowledge from one employee to another. Since hazardous materials management represents an expansive field and knowledge goes along with experience, a technical documentation is essential for knowledge transfer.

\subsection{HMM-System Audit}

Against the background of the increasing number and the frequent amendment of environmental legislations as well as internal changes (e.g. employee fluctuation, restructuring), the process reliability of HMM has to be tested continuously. Therefore, an internal system audit is necessary. A reasonable approach is the simulation of an enforcement audit that covers the analysis of a single product and tests all relevant features according to a specific regulation. In this context, it has to be analyzed at every step of HMM if all relevant information are gathered and provided in an appropriate environment and each employee understands its responsibilities regarding the specific regulation.

\section{Applicability and Discussion}

Generally, SME suffer more greatly from substances restrictions, e.g. RoHS.$^{50}$ The herein presented approach to an integrated hazardous substances management (HMM) has, however, proved to be applicable to all businesses, as it has been applied successfully in over 70 companies of different size, turnover, quantity of materials and suppliers in various industries in Germany. However, details of each project cannot be illustrated within this paper due to non-disclosure agreement with our partners. In this section we thus discuss the applicability of HMM to different types of companies based on four main characteristics: turnover, quantity of employees, materials and suppliers.
The EU distinguishes four types of companies regarding their turnover and quantity of employees. ${ }^{49}$ As quantity of materials and suppliers are of major interest to HMM, we extend the examination as displayed in Table 5.

Appendix B displays a summary of frequent obstacles and recommendations for implementation of HMM related to each business type. Although the required time frame for an HMM implementation is comparatively short, micro and small companies generally suffer from a deficit of awareness, knowledge and capacity. Additionally, the common absence of standard processes hampers the adoption of HMM measures and responsibilities. Micro and small companies therefore largely benefit from participation at relevant seminars and external product analysis. HMM implementation at medium and large companies will require much longer (1 to 2 years) due to its bureaucratic structures and comparatively long information processes. Although few top managers at medium and large companies indicate a lack of awareness, these companies mostly have gathered experience with environmental legislations. HMM may thus be adopted to the standard processes more easily. These companies, however, suffer from the little incentives given to employees to change the organization. Another frequent obstacle when trying to implement HMM, especially at large companies, is the unclear process landscape, data management and IT surroundings. Experience shows that even employees being affiliated with a large company for many years do not have a complete overview of their system surroundings. Depending on their size, the appointment of an appropriate number of full-time positions related to environmental legislations is inevitable.

\section{Summary, Critical Review and Forecast}

A variety of management systems have been discussed in literature and successfully implemented in industries, as discussed in section two. Nevertheless, none of these have been able to fulfill essential requirements of hazardous materials management. In this paper we presented an approach for HMM that has been implemented successfully in over 70 companies of different industries and business types in Germany and is expected to be universally transferable to industrial companies globally. The 14 step approach of HMM covers all legal requirements of REACH and RoHS regarding articles. It, however, has shown diverse applicability to various industries, essentially being influenced by turnover, quantity of employees, materials and suppliers.

Although complete elimination of risk might not be possible, HMM comprises all essential elements of legal environmental compliance in the field of hazardous materials. Nevertheless, the approach currently

Table 5 Business types*

\begin{tabular}{ccccc}
\hline & $\begin{array}{c}\text { Employees } \\
\text { (quantity) }\end{array}$ & $\begin{array}{c}\text { Turnover } \\
(€)\end{array}$ & $\begin{array}{c}\text { Quantity of } \\
\text { materials }\end{array}$ & $\begin{array}{c}\text { Quantity of } \\
\text { suppliers }\end{array}$ \\
\hline Micro & $<10$ & $\leq 2 \mathrm{~m}$ & $\leq 100$ & $\leq 10$ \\
\hline Small & $<50$ & $\leq 10 \mathrm{~m}$ & $\leq 1.000$ & $\leq 100$ \\
\hline Medium & $<250$ & $\leq 50 \mathrm{~m}$ & $\leq 10.000$ & $\leq 1.000$ \\
\hline Large & $>250$ & $>50 \mathrm{~m}$ & $>10.000$ & $>10.000$ \\
\hline
\end{tabular}

*Author's own compilation based on EU classification 
exhibits flaws in certain range areas. This especially applies to the observation of substance being used only in processes that not remain in the product itself. The appliance of certain hazardous substances is regulated under REACH as well, as they pose a threat employees and the environment. Beyond that, further research is needed to identify the influence of the quantity of products and active markets of a single company on HMM applicability.

On a long term, against the background of the dramatically increasing global amount of environmental legislations, the implementation of a standardized HMM system as proposed in this paper is essential for nearly every industrial company. In turn, governments and law enforcement agencies are requested to adjust activities and find interfaces in order to reduce complexity of business. A fair balance of legal requirements and industrial expenses has to be realized in order to guarantee success of environmental policies.

Additionally, extended research is needed on a downstream basis in order to provide governments with accurate information on the status of implementation of different legislations. Traditionally, communication between governments and industries is poorly distinctive and circular. Novel methods are needed, e.g. for quantification of obsolescence potentials of certain substances and technologies.

\section{REFERENCES}

1. OECD, "Sustainable Manufacturing Toolkit: Seven Steps to Environmental Excelence," http://www.oecd.org/innovation/green/ toolkit/48661768.pdf (Accessed 3 June 2015)

2. Compliance and Risk, "C2P Global Regulations by Subject Area (Entred into Force 2003-2010),” 2011.

3. European Union, "Directive 2000/53/EC of the European Parliament and of the Council of 18 September 2000 on End-of-Life Vehicles," Official Journal of the European Union, pp. 34-43, 2000.

4. European Union, "Richtlinie 2002/96/EG des Europäischen Parlaments und des Rates Vom 27. Januar 2003 über Elektro- und Elektronik-Altgeräte," Official Journal of the European Union, pp. 24-39, 2003.

5. European Union, "Directive 2011/65/EU of the European Parliament and of the Council of 8 June 2011 on the Restriction of the Use of Certain Hazardous Substances in Electrical and Electronic Equipment," Official Journal of the European Union, pp. 88-110, 2011.

6. European Union, "Regulation (EC) No. 1907/2006 of the European Parliament and of the Council of 18 December 2006 Concerning the Registration, Evaluation, Authorisation and Restriction of Chemicals (REACH), Establishing a European Chemicals Agency, Amending Directive 1999/45/EC and Repealing Council Regulation (EEC) No. $793 / 93$ and Commission Regulation (EC) No. 1488/94 as well as Council Directive 76/769/EEC and Commission Directives 91/155/ EEC, 93/67/EEC, 93/105/EC and 2000/21/EC," Official Journal of the European Union, pp. 1-849, 2006.
7. European Union, "Regulation (EC) No. 842/2006 of the European Parliament and of the Council of 17 May 2006 on Certain Fluorinated Greenhouse Gases," Official Journal of the European Union, pp. 1-11, 2006.

8. Handelsblatt, "Kältemittel-Streit: Freie Fahrt für Daimler in Frankreich," 2013.

9. European Commission, "Rapid Alert System for Non-Food Dangerous Products," http://ec.europa.eu/consumers/consumers_safety/ safety_products/rapex/index_en.htm (Accessed 2 March 2015)

10. MITSloan, "The New Industrial Engineering: Information Technology and Business Process Redesign," http://sloanreview.mit.edu/ article/the-new-industrial-engineering-information-technology-andbusiness-process-redesign/ (Accessed 12 April 2014)

11. Scheer, A.-W. and Nüttgens, M., "Aris Architecture and Reference Models for Business Process Management,” Springer, pp. 376-389, 2000 .

12. Münstermann, B., Eckhardt, A., and Weitzel, T., "The Performance Impact of Business Process Standardization: An Empirical Evaluation of the Recruitment Process," Business Process Management Journal, Vol. 16, No. 1, pp. 29-56, 2010.

13. Muenstermann, B., Von Stetten, A., Laumer, S., and Eckhardt, A., "The Performance Impact of Business Process Standardization: HR Case Study Insights," Management Research Review, Vol. 33, No. 9, pp. 924-939, 2010.

14. Beimborn, D., Gleisner, F., Joachim, N., and Hackethal, A., "The Role of Process Standardization in Achieving It Business Value," Proc. of the Hawaii International Conference on System Sciences, 2009. pp. 1-10, 2009.

15. ISO No. 9000, “Quality Management,” 2005.

16. ISO No. 14000, "Environmental Management,” 2009.

17. ISO No. 50001, “Energy Management,” 2011.

18. European Union, "Regulation (EC) No. 1221/2009 of the European Parliament and of the Council of 25 November 2009 on the Voluntary Participation by Organisations in a Community EcoManagement and Audit Scheme (EMAS), Repealing Regulation (EC) No. 761/2001 and Commission Decisions 2001/681/EC and 2006/193/EC 2009," Official Journal of the European Union, pp. 1$45,2006$.

19. Jeffrey, T., "Compliance Management System," Verlag AlexInformation, 2004.

20. Klaus, M., “Compliance: Praxisleitfaden für Unternehmen,” C.H. Beck, 2010.

21. Christoph, B., Stefan, B., Ina, B., Alfred, D., David, E., et al, "Compliance: Aufbau, Management, Risikobereiche," C.F. Müller; 2010.

22. Wieland, J. and Steinmeyer, R., "Handbuch Compliance-Management Konzeptionelle Grundlagen, Praktische Erfolgsfaktoren, Globale Herausforderungen,” Erich Schmidt Verlag, 2010. 
23. Knight, F. H., "Risk, Uncertainty and Profit," New York: Hart, Schaffner and Marx, 1921.

24. Rescher, N., "A Philosophical Introduction to the Theory of Risk Evaluation and Measurement," University Press of America, 1983.

25. Drake, R., "Decision Making and Risk Taking: Neurological Manipulation with a Proposed Consistency Mediation," Contemporary Social Psychology, Vol. 11, pp. 149-152, 1985.

26. Holton, G. A., "Defining Risk," Financial Analysts Journal, Vol. 60, No. 6, pp. 19-25, 2004.

27. Hillson, D. and Simon, P., "Practical Project Risk Management: The Atom Methodology,” Management Concepts, 2007.

28. ISO No. 31000, "Risk Management,” 2009.

29. ISO/DIS No. 31000 "Risk management - Principles and Guidelines on Implementation," 2009.

30. European Commission, “Amending Annex II to Directive 2011/65/ EU of the European Parliament and of the Council as Regards the List of Restricted Substances," pp. 1-2, 2014.

31. EUR-Lex, "Der Zugang Zum EU-recht," http://eur-lex.europa.eu/ homepage.html?locale=de (Accessed 12 April 2014)

32. ECHA, "European Chemicals Agency," http://echa.europa.eu/documents/ 10162/13585/press_memo1_20080603_en.pdf(Accessed 10 April 2014)

33. Compliance and Risk, "C2P: What is CWP?" http://www. complianceandrisks.com/services/c2p/ (Accessed 10 February 2014)

34. European Union, "Decision No. $768 / 2008 /$ EC of the European Parliament and of the Council of 9 July 2008 on a Common Framework for the Marketing of Products, and Repealing Council Decision 93/465/EEC," Official Journal of the European Union, pp. 82-128, 2008.

35. European Union, "Regulation (EC) No. 765/2008 of the European Parliament and of the Council of 9 July 2008 Setting Out the Requirements for Accreditation and Market Surveillance Relating to the Marketing of Products and Repealing Regulation (EEC) No. 339/93," Official Journal of the European Union, pp. 30-47, 2008.

36. BS EN 50581:2012, “Technical Documentation for the Assessment of Electrical and Electronic Products with Respect to the Restriction of Hazardous Substances," 2012.

37. Beucker, S., Westkämper, E., Bullinger, H.-J., and Spath, D., "Ein Verfahren zur Bewertung von Lieferanten auf der Grundlage von Umweltwirkungen unter Berücksichtigung von Prozesskosten," Jostjetter Verlag, http://elib.uni-stuttgart.de/opus/volltexte/2006/2461/ pdf/Diss_Beucker_hs.pdf (Accessed 4 June 2015)

38. Transparancy International, "Corruption Perceptions Index: Overview," www.transparency.org/research/cpi/overview, (Accessed 11 April 2014)

39. ZVEI, "Materialdeklarationen Innerhalb der Lieferkette," http:// www.zvei.org/Publikationen/ZVEI-Leitfaden-Materialdeklarationeninnerhalb-der-Lieferkette.pdf (Accessed 4 June 2015)
40. ISO No. 14040:2006, "Environmental Management -- Life Cycle Assessment -- Principles and Framework,” 2006.

41. ISO No. 14044:2006, "Environmental Management -- Life Cycle Assessment -- Requirements and Guidelines,” 2006.

42. International Electrotechnical Commission, "IEC 62474 - Material Declaration for Products of and for the Electrotechnical Industrym," 2013.

43. International Electrotechnical Commission, "IEC 62321-2 Determination of Certain Substances in Electrotechnical Products Part 2: Disassembly, Disjunction and Mechanical Sample Preparation," 2013.

44. Hu, A. H., Hsu, C.-W., Kuo, T.-C., and Wu, W.-C., "Risk Evaluation of Green Components to Hazardous Substance Using FMEA and FAHP," Expert Systems with Applications, Vol. 36, No. 3, pp. 71427147, 2009.

45. SAP, "SAP Product and REACH Compliance 2.0," http:// help.sap.com/reach20 (Accessed 11 February 2014)

46. SAP, "SAP Product Stewardship Network," http://www.sap.com/pc/ tech/cloud/software/product-stewardship-network/overview/ index.html (Accessed 11 April 2014)

47. Hewlett-Packard, "HP Compliance Data Exchange (CDX)," http:// www8.hp.com/de/de/business-solutions/ solution.html?compURI=1330154\#.U1YTTxAXsQA, (Accessed 11 April 2014)

48. PTC, "PTC Materials Compliance Solution," http://de.ptc.com/ solutions/materials-compliance/ (Accessed 10 April 10 2014)

49. European Commission, "What is an SME?" http://ec.europa.eu/ enterprise/policies/sme/facts-figures-analysis/sme-definition/ index_en.htm (Accessed 2 March 2015)

50. Maag, J., Brandt, U. K., Mikkelsen, S. H, and Lassen, C., "Inclusion of HBCDD, DEHP, BBP, DBP and Additive Use of TBBPA in Annex IV of the Commission's Recast Proposal of the RoHS Directive - Socioeconomic Impacts," Danish Ministry of the Environment, Document No. 13172010, 2010. 


\section{APPENDIX A. HMM Process}

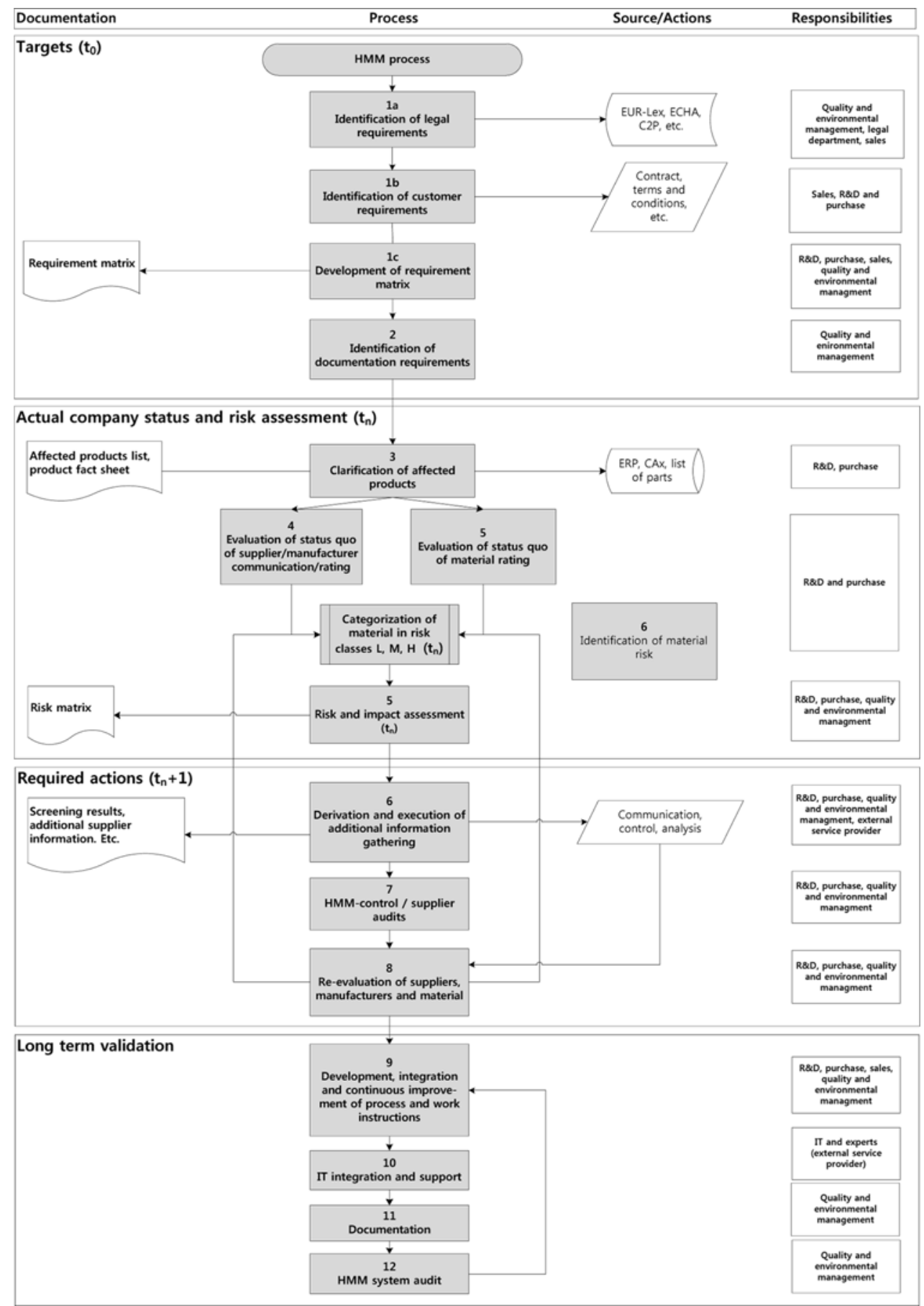

APPENDIX B. Applicability of HMM Related to Different Business Types

\begin{tabular}{|c|c|c|c|c|}
\hline & Micro & Small & Medium & Large \\
\hline Approx. time span require & 2 months & 4 months & 1 year & 2 years \\
\hline $\begin{array}{c}\text { Frequently } \\
\text { occurring } \\
\text { obstacles }\end{array}$ & $\begin{array}{c}\text { - Deflict of awareness, } \\
\text { knowledge, capacity } \\
\text { - No existing standard } \\
\text { processes }\end{array}$ & $\begin{array}{l}\text { - Deflict of awareness, } \\
\text { knowledge, capacity } \\
\text { - No existing standard } \\
\text { processes }\end{array}$ & $\begin{array}{l}\text { - Deflict of awareness } \\
\text { of top manager } \\
\text { - Little incontives to } \\
\text { change organization }\end{array}$ & $\begin{array}{c}\text { - Confusing process landscape, } \\
\text { data management, } \\
\text { IT surroundings } \\
\text { - Deficit of awareness } \\
\text { of top managers } \\
\text { - Little incentives to } \\
\text { change organization }\end{array}$ \\
\hline Recommendations & $\begin{array}{l}\text { - Participation at } \\
\text { relevant seminars, } \\
\text { external product analysis }\end{array}$ & $\begin{array}{l}\text { - Participation at } \\
\text { relevant seminars, } \\
\text { external product analysis }\end{array}$ & $\begin{array}{l}\text { - Appointment of one } \\
\text { full-time position }\end{array}$ & $\begin{array}{l}\text { - Appointment of three } \\
\text { full-time positions }\end{array}$ \\
\hline
\end{tabular}

